\title{
Primary discussion on the integration of university national vocal music education and original folk songs
}

\author{
Xiao Wang \\ Collage of Music, China West Normal University, Nanchong, 637009, China
}

Keywords: University, National vocal music education, Original folk song, Integration.

\begin{abstract}
Original folk songs are China's important national art treasure and the source for innovative development of Chinese national music. With high social value and art value, original folk songs as China's important intangible cultural heritage are of great significance to transmit Chinese excellent national culture. Integrating original folk songs into university national vocal music education will have great function on the inheritance and development of excellent national culture, improvement of students' comprehensive quality, national vocal musical teachers' teaching level. The paper has discussed the connotation of original folk songs and explored the spiritual cultural value, and then explored the function of integrating university national vocal education and original folk songs, and then proposed several comments on how to integrate original folk songs with university national vocal education.
\end{abstract}

\section{Introduction}

Music can inspire people's wisdom and improve people's creativity and imagination through people's hearing organs. Music development level represents the country's cultural and artistic level. Original folk songs are crystals of laboring people's wisdom, as well as the important contents of China's music art with high artistic cultural value. Natural style singing showed in $12^{\text {th }}$ National Young Singers' Competition held by CCTV in 2006, then people had new understanding and inspiration of the colorful expression mode of original folk songs and the simple and pure emotions of folk songs. A lot of musicians have realized there are broad development and utilization space in original folk songs. Some scholars think that integrating original folk songs into university national vocal music education can inherit and protect original folk song, the intangible cultural heritage, and can improve students' comprehensive quality and teachers' teaching level. Thus, it has a lot of benefits.

\section{Current situation of university national vocal music education}

\section{Selection of teaching materials}

Currently, teaching songs used in Chinese university national vocal and musical education are of strong national style which are in descriptive style. Through continuous modification and innovation, they finally become large-scale vocal music works. This measure has broadened the range of Chinese national vocal music, and can fully display the wonderful artistic conception of songs through vocal variety.

\section{Teaching methods}

Currently, methods such as imitation and learning bel canto are often used in Chinese university national vocal music education to break through the national vocal music performance technique and style. For example, unifying three phonation through the singing technique of the combination of true voice and falsetto voice can establish the pronunciation and articulation of national charm on good 
breath, and can make the singing smooth. Also performers' musical quality can be better and their singing is more expressive.

\section{Teaching limit}

A lot of vocal music universities will fall into the pursuit of classicism phonation principle and aesthetics during the process of carrying out vocal music education. Some national vocal teachers usually pay excessive attention to the singing standard and singing form of western vocal music during teaching process. The teaching method usually makes students' signing style are similar. A lot of singers receiving professional training cannot fully express the national charm of the song with national style. Due to teaching limit, a lot of university national vocal music students know little about the national culture contained in national songs. They usually ignore some key details during the process of learning and extending songs.

\section{Original folk songs are of high natural cultural value}

National music as the source and foundation of China's music development has unique aesthetic value, cultural mechanism and artistic personality. Original folk songs are important component of China's national music culture. Since the reform and opening-up, in front of severe impact from exterior culture, a lot of people start doubting the spiritual value and cultural value of Chinese national music culture, which brings serious obstacles to China's national music development. Original folk song as a dynamic culture has unique artistic quality and cultural value and can bring spiritual comfort and artistic enjoyment to people, and can effectively improve people's aesthetic interest, improve cultural identity and sense of national pride.

Original folk song is China's important national art treasure, important intangible cultural heritage, and the source for innovative development of Chinese national music. Folk art has been important creation for national artists to obtain inspiration and create materials. Even some vocal music works have referred to artistic techniques of western vocal music, more creation contents are Chinese national folk music. Original folk songs have long history with solid mass base and huge development potential. Learning and imitating original folk song singing technique is of great positive significance to get rid of simplification. Looking for vitality among the people when creating national vocal music can effectively enrich the artistic expression techniques and cultural value of music works, and get more people to like it. Audiences can effectively improve their own aesthetic ability and appreciation ability through learning and listening to excellent national vocal music works.

\section{The significance of integrating original folk songs with university national vocal music education}

Original folk songs as the treasure of China's traditional music art is showing its artistic value and social value at preset with the diversified development culture. Universities are importance places to inherit and promote China's excellent national culture. As China's important intangible cultural heritage, original folk song is the importance channel to transmit and promote China's excellent culture. Under the time background of diversified development of music culture, integrating original folk songs with university national vocal music education is of great significance for the development of China's national music culture.

\section{It can greatly enrich the contents of university vocal music education}

Original folk songs are not widely spread as it has strong regional property. It is mainly transmitted by word of mouth. Original folk songs are not specially organized, so most of the tones and lyrics are random so that they get lost easily during the process of inheritance. National vocal music colleges have advantageous talent and resource advantage so they can improve the art value of original folk songs by virtue of own advantages and better inherit and develop original folk songs. We 
can say original folk song can be better promoted by virtue of university national vocal music education which can enrich teaching contents through original folk songs so as to promote its innovation development. Currently, there are more than 700 universities setting national vocal music education courses in China which use similar teaching modes. Influenced by the concept of western music remoulds Chinese traditional national music, Chinese university national vocal music teaching only focuses on training singing techniques but ignores the study of traditional national music culture and the connotation. This traditional teaching mode is format oriented and not good for students to learn, appreciate and absorb other forms of music. It has also brought obstacles for the development of national music. University national vocal music education is urgent to introduce original folk songs to improve the current teaching condition. Original folk songs have abundant expression forms which can effectively improve the vitality of national vocal music education,

Integrating original folk songs in university national vocal music education can help guide students to comprehensively and profoundly learn and study original folk songs, and inherit and develop original folk songs. During the process, university teachers will compile original folk songs and re-set vocal music courses according to the grade and specialty which has positive significance for students to directly and comprehensively understand original folk songs, and also help better understand Chinese traditional national music culture, inherit and promote Chinese traditional national music culture.

\section{It can effectively improve students' creativity and imagination}

Original folk songs as the wisdom crystal of massive laboring people has strong regional features and widely distribution. The singing techniques and expression forms in each area are different. Students can effectively improve their imagination and creativity through learning and studying original folk songs. When teaching original folk songs, teachers can encourage students to conduct field investigation on the source area of original folk songs so as to profoundly understand the formation, background of transmission, and national culture and style of original folk songs. This teaching method can effectively improve students' thinking, help students master and use musicality. Students can comprehensively and profoundly understand the essence of original folk songs and improve their own musical creativity.

\section{It can help improve students' comprehensive quality}

At present, the society pays more and more attention to people's comprehensive quality. Universities as the major talent output places must keep improving the cultivation of students' comprehensive quality. China's quality-oriented education requires to cultivate talents with lofty ideals, moral integrity, better education and good sense of discipline. Thus educational objectives of university music education should be cultivating youngsters with four virtues. Music cultural education is of great significance for cultivating and improving students' comprehensive quality. Music left in original folk songs which have been tested by thousands of years are basically classic. Students learn these classic works to cultivate their appreciation ability, and they can have a taste of predecessors' love for life and nature. Thus more talents with high comprehensive quality can be cultivated in higher primary schools.

\section{It can help improve university students' national cultural identity and sense of national pride.}

Music as an art carried the thinking of creation in each musical work will integrate Chinese national spiritual culture in the process of transmission and development. Original folk songs with regional property show labor people's life style and aesthetic concept, cultural value and national spirit. Original folk song teaching can cultivate university students' understanding and identity of Chinese excellent national culture and national spirit, improve their sense of national pride and belongingness, and help them shoulder the historic mission of transmitting, developing and promoting Chinese excellent national culture and spirit. 


\section{Effective measures to integrate original folk songs into university vocal music education}

\section{Expand university music teacher troop}

With continuous improvement of the society and people's mind, university music teacher should keep up with the time development, actively change teaching concept so as to satisfy requirements of society for talents and students' own development requirements. Firstly, university music teachers should take the initiative to learn new thing, absorb some successful teaching theories and methods, continuously perfect Chinese national vocal culture system, improve their own teaching level. Secondly, actively participate in music art training and art communication activities and improve music cultural connotation and music apperception, expand their own music cultural view, and apply what they have learned in teaching activities reasonably. Thirdly, university national vocal music teaching specialty should improve investment in special funds and create more opportunities for learning and exchange. Fourthly, university music teachers can obtain more scientific teaching experience through listening to other teachers' lectures, and improve the whole teaching quality and level through teaching resource and knowledge sharing. At last, university national vocal music teaching specialty should actively break through the limitation of diploma and professional title, hair high-level folk artists for music teaching so as to continuously improve the strength of national vocal music teaching team.

\section{Abide by relevant principles.}

The creation source of original folk songs come from people' daily life containing various contents. So while introducing original folk songs, try to select positive and national characteristic songs, abandon and innovate these songs based on teaching requirements and time development. Influenced by living environment, life style, folk custom and regional factors, China's original folk songs are of various singing forms and musical themes. So university national vocal music teaching should be in line with inclusiveness principle and accept the diversity while integrating original folk songs.

\section{Encourage cultural exchange}

Introducing original folk songs into university national vocal music teaching can help inherit China's excellent national culture, innovate university national vocal music content, and improve national vocal music teaching effect. On the other hand, it can strengthen the exchange with other national original folk music culture, absorb excellent contents and promote China's original folk songs to obtain long-term development.

\section{Innovate and perfect teaching methods}

Students of different specialties and grades have different music level. University national vocal music teachers should choose suitable teaching methods based on students' specialty and music level. Only through perfecting teaching methods constantly, innovating teaching technique can vocal music teaching effect be improved. University vocal music teachers can organize students to experience original folk songs personally in the source place of original folk songs to improve students' creation inspiration and music comprehensive quality.

\section{Conclusion}

University national vocal music and original folk songs are treasures in Chinese national music treasury vault and singing techniques of both have their own features and close correlation. Original folk songs are the source for national vocal music to keep innovative development. Only through keeping up with the time development can original folk songs keep innovative development and provide endless power for the development of Chinese national vocal music. It is necessary to excavate and explore the element of original folk songs in national vocal music during the process of university national vocal music education, pay attention to guide students to profoundly understand the cultural connotation and national style of national vocal music songs. In this way, even bel canto 
will not fall into western standardization. This teaching method can truly and accurately solve the traditional and modern issues, and fully manifest the teaching characteristic that university national vocal music education based on nation can make the past serve the present.

\section{Acknowledgements}

China West Normal University Excellent Talent Plan "Studies on the application of regional characteristic folk songs in university vocal music education" (Project number: 17YC552), China West Normal University innovation team "Studies on Bashu folk musical culture and database construction" (Project number: CXTD2016-8).

\section{References}

[1] Ying Na. Discussion on the enlightenment of original folk songs integration into university vocal music teaching, Art Educaiton, 2016 (9) :82- 83.

[2] He Yimin. Discussion on the necessity of introducing original folk songs to university music class-Take Sangzhi folk songs as the example, Music Space Time, 2011,13.

[3] Yang Min. Rethinking the controversy problem of original folk songs, Symphony Journal of Xi'an Conservatory of Music), 2014,01.

[4] He Yimin. Discussion on the necessity of introducing original folk songs to university music class_-Take Sangzhi folk songs as the example, Music Space Time, 2014,13. 